\title{
The effect of mirabegron on patient-related outcomes in patients with overactive bladder: the results of post hoc correlation and responder analyses using pooled data from three randomized Phase III trials
}

\author{
D. Castro-Diaz • C. R. Chapple - Z. Hakimi • \\ M. B. Blauwet • L. Delgado-Herrera • \\ W. Lau $\cdot$ S. Mujais
}

Accepted: 17 December 2014/Published online: 17 February 2015

(c) The Author(s) 2015. This article is published with open access at Springerlink.com

\begin{abstract}
Purpose To understand how improvements in the symptoms of overactive bladder $(\mathrm{OAB})$ seen with the $\beta_{3}$-adrenoceptor agonist mirabegron $50 \mathrm{mg}$, correlate with patient experience as measured by validated and standard patient-reported outcomes (PROs), and to identify whether there is overall directional consistency in the responsiveness of PROs to treatment effect.

Methods In a post hoc analysis of pooled data from three randomized, double-blind, placebo-controlled, 12-week Phase III trials of mirabegron $50 \mathrm{mg}$ once daily, responder rates for incontinence frequency $(\geq 50 \%$ reduction in incontinence episodes $/ 24 \mathrm{~h}$ from baseline to final visit), micturition frequency ( $\leq 8$ micturitions $/ 24 \mathrm{~h}$ at final visit), and PROs [minimally important differences in patient perception of bladder condition (PPBC) and subsets of the overactive bladder questionnaire (OAB-q) measuring total health-related quality of life (HRQoL), and symptom bother] were evaluated individually and in combination.

Results Mirabegron $50 \mathrm{mg}$ demonstrated greater improvement from baseline to final visit than placebo for
\end{abstract}

D. Castro-Diaz ( $\square)$

Department of Urology, University Hospital of the Canary

Islands, Ofra s/n. La Cuesta-38320-La Laguna,

Santa Cruz de Tenerife, Spain

e-mail: davidmanuelcastrodiaz@gmail.com

C. R. Chapple

Department of Urology, Royal Hallamshire Hospital, Sheffield, UK

\section{Z. Hakimi}

Astellas Pharma Global Development, Leiden, The Netherlands

M. B. Blauwet - L. Delgado-Herrera - W. Lau - S. Mujais Astellas Pharma Global Development, Northbrook, IL, USA each of the responder analyses, whether for individual objective and subjective outcomes or combinations thereof. These improvements versus placebo were statistically significant for all double and triple responder analyses and for all single responder analyses except PPBC. PRO measurements showed directional consistency and significant correlations, and there were also significant correlations between objective and subjective measures of efficacy.

Conclusions The improvements in objective measures seen with mirabegron $50 \mathrm{mg}$ translate into a meaningful clinical benefit as evident by the directional consistency seen in HRQoL measures of benefit.

Keywords Mirabegron - Overactive bladder · Patientreported outcomes · Quality of life · Correlation

\section{Introduction}

Overactive bladder (OAB) is defined by symptoms of urinary urgency, usually accompanied by frequency and nocturia, with or without urgency incontinence, in the absence of urinary tract infection (UTI) or other obvious pathology [1]. This condition is estimated to affect $12-17 \%$ of adults in Europe and the USA [2-5]. OAB is associated with anxiety and depression [6-8], impairment of work productivity [9], and daily activities [10-12]. It is therefore associated with detrimental effects on healthrelated quality of life (HRQoL) [13]. Indeed, the severity of urgency urinary incontinence has been shown to be a predictor for HRQoL [14].

Clinical trials of treatments for the symptoms of $\mathrm{OAB}$ have traditionally relied on objective outcome measures to evaluate treatment efficacy, of which the most commonly used are those recorded in a patient bladder diary, namely 
micturition frequency, number of incontinence and urgency episodes in a $24 \mathrm{~h}$ period, number of nocturia episodes per $24 \mathrm{~h}$, and volume voided per micturition $[15,16]$. However, these endpoints say little about the impact that symptoms have on the patient's quality of life (QoL) [17]. Indeed, it has been reported that improvements in objective outcomes do not necessarily correlate with improvements in subjective outcomes, that is, they do not necessarily translate into improvements in HRQoL $[15,16]$. Consequently, there is a growing appreciation of the need to understand health outcomes from the patient's point of view [18-21], particularly for the treatment of chronic debilitating conditions such as $\mathrm{OAB}$, for which treatment is often aimed at symptom management rather than cure. The International Continence Society recommends that QoL measures be evaluated in the assessment of therapeutic interventions for the management of the symptoms of OAB [22].

A patient's likelihood of persisting with a treatment for $\mathrm{OAB}$ is related to their satisfaction with that treatment [23]. Improvements in objective measures, such as micturition frequency, without a concomitant improvement in patientreported measures of HRQoL, may not be sufficient to persuade the patient to persist with treatment. Indeed, improvements in objective outcomes achieved with common $\mathrm{OAB}$ drugs have typically not translated into longterm persistence; persistence rates ranging from 8 to $29 \%$ have been reported in studies with at least 1 year of followup [24-27]. On the other hand, statistically significant improvements from baseline in the patient perception of bladder condition (PPBC) score have been seen in an openlabel study of darifenacin along with treatment satisfaction for $85 \%$ of patients [28].

Mirabegron is the first in a new class of agents-the $\beta_{3}$-adrenoceptor agonists - to be approved for the treatment of $\mathrm{OAB}$. In addition to objective bladder diary outcome measures, a range of PROs were evaluated in three randomized, doubleblind, placebo-controlled, 12-week Phase III clinical trials (Studies 046 (NCT00689104) [29], 047 (NCT00662909) [30], and 074 (NCT00912964) [31]). Co-primary (objective) outcome measures in all three studies were change from baseline to final visit in mean number of micturitions per $24 \mathrm{~h}$ and mean number of incontinence episodes per $24 \mathrm{~h}$. Patient-reported outcomes (PROs) included the overactive bladder questionnaire $(\mathrm{OAB}-\mathrm{q})$, the $\mathrm{PPBC}$, and the treatment satisfaction visual analog scale (TS-VAS). In all three Phase III studies, and in a pre-specified, pooled analysis of the three studies [32], mirabegron $50 \mathrm{mg}$ once daily resulted in statistically significant improvements from baseline to final visit versus placebo on both co-primary outcomes. It also resulted in a statistically significant improvement from baseline to final visit compared with placebo on PPBC as well as on the symptom bother scale and total HRQoL of the OAB-q in all three studies and the OAB-q subscales of coping and concern in Studies 046 and
047. Statistically significant improvement relative to placebo in the OAB-q subscale of sleep was also reported with mirabegron $50 \mathrm{mg}$ in Study 047. In the pooled analysis, the only PRO reported was the TS-VAS; this too showed a statistically significant improvement from baseline to final visit for mirabegron $50 \mathrm{mg}$ versus placebo. Analysis of the pooled data has also shown greater improvement in the EQ-5D utility score with mirabegron $50 \mathrm{mg}$ compared with placebo and tolterodine [33].

This paper presents the results of post hoc analysis conducted on the large pooled mirabegron $50 \mathrm{mg}$ and placebo data sets described above to determine correlations between various objective and subjective outcome measures utilized in the three Phase III trials. (The $25 \mathrm{mg}$ dose was not evaluated in this post hoc analysis as it was used in Study 074 only and hence was not part of the pooled analysis.) Data showing the effects of mirabegron $50 \mathrm{mg}$ on measures of HRQoL are also presented. In a novel approach to understanding these data, responder analyses were performed to assess the proportion of patients who were simultaneously responders for incontinence episodes and micturitions along with one or two different PROs at final visit. The aims were twofold: firstly, to understand how improvements in objective measures with mirabegron $50 \mathrm{mg}$ correlate with the patient's experience as measured by validated, standard PRO instruments and secondly, to understand how improvements in different PRO outcomes correlate with one another. This is of interest because PROs assess different components of the response of patients, resulting in heterogeneity in responsiveness to treatment effect.

\section{Methods}

\section{Study design}

An overview of the design of Studies 046, 047, and 074 is provided in Table 1. Importantly, all three studies were of identical design, the only difference being the inclusion of tolterodine as an active control in Study 046 (but not Studies 047 or 074 ) and the use of mirabegon $25 \mathrm{mg}$, but not mirabegron $100 \mathrm{mg}$ in Study 074.

\section{Efficacy assessments}

\section{Objective measures}

Co-primary efficacy outcome measures in all three studies were change from baseline to final visit in mean number of incontinence episodes per $24 \mathrm{~h}$ and change from baseline to final visit in mean number of micturitions per $24 \mathrm{~h}$. A responder for incontinence episodes was defined as a patient 
Table 1 Overview of design of Studies 046, 047, and 074

\begin{tabular}{|c|c|c|c|c|c|}
\hline Study & Location & Study design & Duration of treatment ${ }^{\dagger}$ & Inclusion criteria $^{\dagger}$ & Treatment groups \\
\hline 046 & $\begin{array}{l}189 \text { sites in } \\
\text { Australia } \\
\text { and Europe }\end{array}$ & $\begin{array}{l}\text { 046: Phase III, randomized, } \\
\text { double-blind, placebo- and } \\
\text { active-controlled study to } \\
\text { evaluate the efficacy and safety } \\
\text { of mirabegron }\end{array}$ & $\begin{array}{l}\text { 2-week single-blind, } \\
\text { placebo run-in period } \\
\text { followed by } 12 \text {-week } \\
\text { double-blind treatment } \\
\text { period }\end{array}$ & $\begin{array}{l}\text { Female and male adults aged } \\
\geq 18 \text { years who had symptoms of } \\
\text { OAB (urinary frequency and } \\
\text { urgency with or without } \\
\text { incontinence) for } \geq 3 \text { months and }\end{array}$ & $\begin{array}{l}\text { Placebo } \\
\text { Mirabegron } 50 \mathrm{mg} \text { od } \\
\text { Mirabegron } 100 \mathrm{mg} \text { od } \\
\text { Tolterodine ER } 4 \mathrm{mg} \text { od }\end{array}$ \\
\hline 047 & $\begin{array}{l}132 \text { sites in } \\
\text { Canada and } \\
\text { USA }\end{array}$ & $\begin{array}{l}047 \text { and } 074 \text { : Phase III, } \\
\text { randomized, double-blind, } \\
\text { placebo-controlled studies to } \\
\text { evaluate the efficacy and safety }\end{array}$ & & $\begin{array}{l}\geq 8 \text { micturitions per } 24 \text { h during } \\
\text { 3-day micturition diary period } \\
\text { collected during run-in period and } \\
\geq 3 \text { urgency episodes (PPIUS scale } \\
\text { grade } 3 \text { or } 4 \text { ), with or without }\end{array}$ & $\begin{array}{l}\text { Placebo } \\
\text { Mirabegron } 50 \mathrm{mg} \text { od } \\
\text { Mirabegron } 100 \mathrm{mg} \mathrm{od}\end{array}$ \\
\hline 074 & $\begin{array}{l}151 \text { sites in } \\
\text { Canada, } \\
\text { USA, and } \\
\text { Europe }\end{array}$ & of mirabegron & & $\begin{array}{l}\text { incontinence during 3-day } \\
\text { micturition diary period collected } \\
\text { during run-in period }\end{array}$ & $\begin{array}{l}\text { Placebo } \\
\text { Mirabegron } 25 \mathrm{mg} \text { od } \\
\text { Mirabegron } 50 \mathrm{mg} \text { od }\end{array}$ \\
\hline
\end{tabular}

$O A B$ overactive bladder, $o d$ once daily, PPIUS Patient Perception of Intensity of Urgency Scale

${ }^{\dagger}$ All three studies

who had incontinence at baseline and $a \geq 50 \%$ decrease from baseline to final visit in mean number of incontinence episodes per $24 \mathrm{~h}$. A responder for micturition frequency was defined as a patient with $\leq 8$ micturitions per $24 \mathrm{~h}$ at final visit. (Note that the results of a responder analysis of incontinence frequency have been reported for Studies 046 and $074[29,31]$ as have the results of responder analyses of both incontinence and micturition frequency in a pooled analysis of all three studies [32].)

\section{Subjective measures}

Patient-reported outcomes evaluated in all three studies include change from baseline to final visit in PPBC, OAB-q symptom bother scale, OAB-q total HRQoL, and the OAB-q subscales of coping, concern, sleep, and social interaction. The PPBC was developed as a global assessment of bladder condition that asks patients to rate their subjective impression of their current bladder condition on a 6-point Likert scale, ranging from 1 ("my bladder condition does not cause me any problems at all") to 6 ("my bladder condition causes me many severe problems"). The OAB-q symptom bother scale measures level of bother associated with $\mathrm{OAB}$ symptoms and is assessed using the eight items that comprise the symptom bother scale of the 33-item OAB-q. Total HRQoL, measured using the remaining 25 items of the OAB$\mathrm{q}$, is comprised of four subscales-coping, concern, sleep, and social interaction. Both the PPBC and the OAB-q have been validated in clinical and community settings and have demonstrated reliable internal consistency, test-retest reliability, construct validity, and responsiveness among patients with a range of OAB symptoms [34-38].

Patient perception of bladder condition was assessed at baseline and week 12/final visit. Higher scores on the PPBC indicate a poorer perception of bladder condition and negative values for change from baseline scores indicate improvement. OAB-q was assessed at baseline and weeks 4,8 , and 12/final visit, and scores transformed onto a $0-100$ scale. OAB-q total HRQoL and subscale scores are directly related to patient wellbeing with higher scores indicating better QoL and a positive change in scores indicating improvement. The score on the OAB-q symptom bother scale is directly related to the degree of patient discomfort (bother) with the symptoms of OAB. Hence, lower scores on this scale indicate a better QoL, and a negative change in the symptom bother scale indicates improvement.

For the responder analysis of PROs, a responder was defined as a patient who achieved a change from baseline to final visit that exceeded the minimally important difference (MID), which is defined as "the smallest difference in score in the domain of interest that patients perceive as beneficial and which would mandate, in the absence of troublesome side effects and excessive costs, a change in patient management" [39]. The MID has been defined to be 10 points for OAB-q (symptom bother, total HRQoL, and subscales) based on anchor and distribution methods [34, 40, 41] and 1 point for PPBC [38].

\section{Statistical analyses}

The full analysis set (FAS) in all three studies comprised all randomized patients who received at least one dose of study drug and had at least one micturition measurement in a 3-day micturition diary at baseline and at least one postbaseline diary. The FAS-incontinence (FAS-I) population comprised FAS patients who also recorded at least one incontinence episode in the 3-day baseline diary. Data for the placebo and mirabegron $50 \mathrm{mg}$ arms of all three studies 
were pooled and change from baseline data analyzed using analysis of covariance (ANCOVA) with treatment group, sex, and study as fixed factors and baseline as a covariate. Pooling of the data was facilitated by the fact that all three studies were identical in design, with the same inclusion and exclusion criteria and outcome measurements (Table 1). Responder rates for PROs, individually and in combination with responder rates for incontinence frequency and micturition frequency, were determined: the double responder analysis involved evaluation of the proportions of patients who were simultaneously responders for either incontinence or micturitions as well as PPBC, OAB-q symptom bother scale, or OAB-q total HRQoL; the triple responder analysis involved evaluation of the proportions of patients who were simultaneously responders for either incontinence or micturitions as well as PPBC and OAB-q symptom bother scale or PPBC and OAB-q total HRQoL. Two-sided $95 \%$ confidence intervals (CIs) for the differences in the proportions of responders between mirabegron $50 \mathrm{mg}$ and placebo are based on normal approximation. Odds ratios, corresponding two-sided $95 \% \mathrm{CIs}$, and $P$ values were derived from a logistic regression model including treatment group, sex, study, and baseline value(s).

Spearman rank partial correlation coefficients, adjusted for baseline, between the objective endpoints (change from baseline to final visit in mean number of incontinence episodes per $24 \mathrm{~h}$ and mean number of micturitions per $24 \mathrm{~h}$ ) and each of the subjective outcomes (OAB-q symptom bother scale, OAB-q total HRQoL, and PPBC) were derived. Additionally, Spearman rank partial correlation coefficients, adjusted for baseline, between change from baseline to final visit in PPBC and change from baseline to final visit in both the OAB-q symptom bother scale and total HRQoL were derived.

\section{Results}

Study population

The pooled placebo and mirabegron $50 \mathrm{mg}$ groups consisted of 1,328 and 1,324 patients in the FAS, respectively, and 878 and 862 in the FAS-I, respectively. Patient demographics and baseline characteristics were similar in the pooled placebo and pooled mirabegron $50 \mathrm{mg}$ treatment groups (Table 2).

\section{Efficacy}

\section{PRO outcomes}

Mirabegron $50 \mathrm{mg}$ resulted in a statistically significant improvement from baseline to final visit relative to placebo in the OAB-q symptom bother scale and PPBC $(P<0.05$, Fig. 1). It also resulted in statistically significant improvements from baseline to final visit relative to placebo in OAB-q total HRQoL and the OAB-q subscales of coping, concern, and sleeping, but not social interaction $(P<0.05$, Fig. 2).

\section{Responder analyses}

The percentage of subjects in the mirabegron $50 \mathrm{mg}$ and placebo groups who were responders (i.e., achieved the MID) at final visit was: 66.0 and $57.8 \%$, respectively, for the OAB-q symptom bother scale, 56.8 and $48.9 \%$ for OAB-q total HRQoL, and 55.9 and $53.1 \%$ for PPBC. Thus, responder rates for the OAB-q symptom bother scale, OAB-q total HRQoL, and PPBC were numerically larger with mirabegron $50 \mathrm{mg}$ than placebo; the odds ratios for

Table 2 Patient demographics and baseline characteristics by pooled treatment group (FAS)

\begin{tabular}{lcc}
\hline & Placebo $(n=1,328)$ & Mirabegron $50 \mathrm{mg}(n=1,324)$ \\
\hline Females $[n(\%)]$ & $966(72.7)$ & $942(71.1)$ \\
Age $($ years), mean (SD) & $59.2(13.2)$ & $59.7(12.6)$ \\
Race $[n(\%)]$ & $1,227(92.4)$ & $1,235(93.3)$ \\
White & $80(6.0)$ & $61(4.6)$ \\
Black or African-American & $13(1.0)$ & $17(1.3)$ \\
Asian & $8(0.6)$ & $11(0.8)$ \\
Other & & $491(37.1)$ \\
Type of OAB [ $(\%)]$ & $442(33.3)$ & $412(31.1)$ \\
Urgency incontinence only & $415(31.3)$ & $421(31.8)$ \\
Mixed stress/urgency incontinence & $471(35.5)$ & $85.2(93.1)$ \\
Frequency/urgency without incontinence & $86.3(99.1)$ & $1.8(2.5)$ \\
Duration of OAB (months), mean (SD) & $1.8(2.5)$ & $11.7(3.2)$ \\
Number of incontinence episodes per 24 h, mean (SD) & $11.6(3.1)$ & \\
Number of micturitions per 24 h, mean (SD) & &
\end{tabular}

$F A S$ full analysis set, $O A B$ overactive bladder, $S D$ standard deviation 
Fig. 1 Adjusted mean change (SE) from baseline to final visit in $\mathbf{a}$ the OAB-q symptom bother scale (FAS) and b PPBC (FAS) with mirabegron $50 \mathrm{mg}$ and placebo (pooled data) (a) OAB-q symptom bother scale (FAS)

(b) PPBC (FAS)

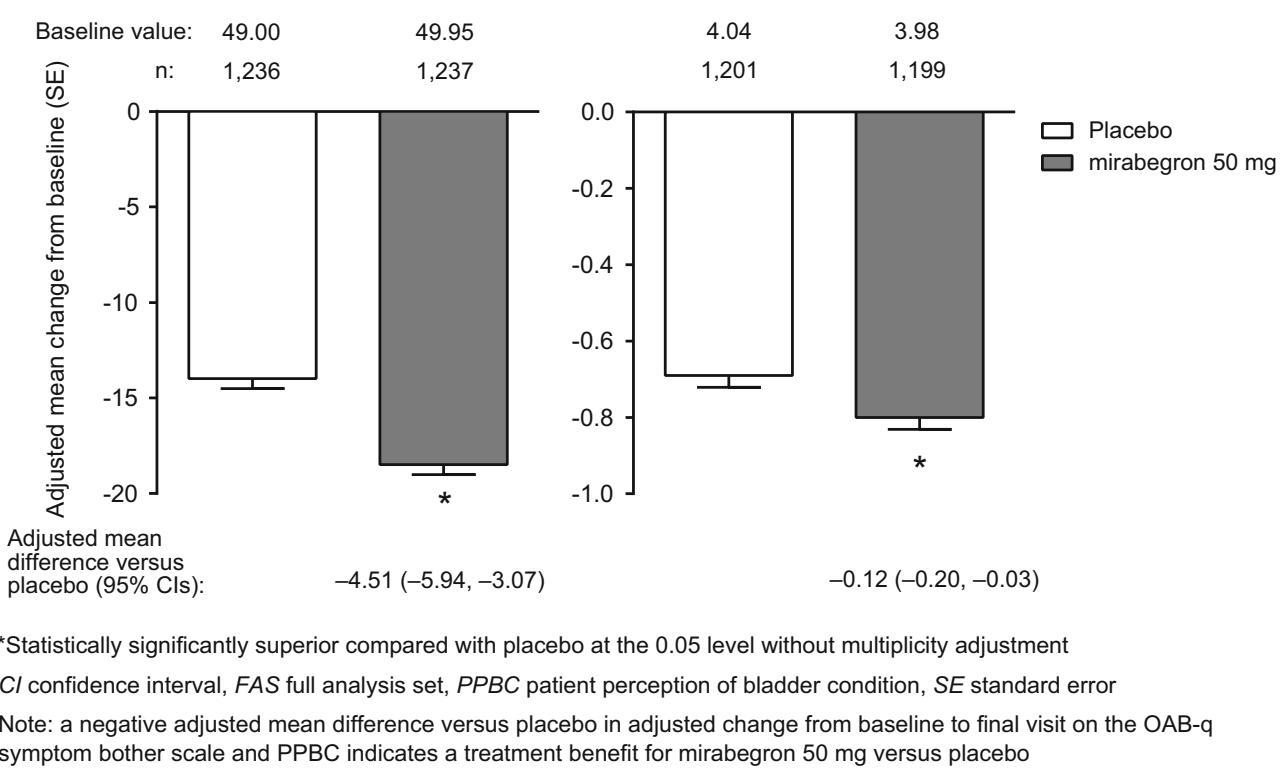

mirabegron $50 \mathrm{mg}$ versus placebo on responder rates were all greater than one (Table 3). The difference in responder rates between mirabegron $50 \mathrm{mg}$ and placebo was statistically significant for the OAB-q symptom bother scale and OAB-q total HRQoL $(P<0.001)$, and it approached, but did not reach, statistical significance for PPBC. (Responder rates for incontinence and micturition frequency were also statistically significantly larger with mirabegron $50 \mathrm{mg}$ than placebo; these results have been reported previously [32] and are shown in Table 3 for completeness.)

When responder rates for incontinence episodes were analyzed in combination with responder rates for PPBC, OAB-q symptom bother scale, or OAB-q total HRQoL to identify patients who were simultaneously responders on two (double responder analysis) or three (triple responder analysis) outcomes, mirabegron $50 \mathrm{mg}$ demonstrated statistically significantly greater responder rates compared with placebo in all analyses $(P<0.001$, Table 3$)$. Likewise, when responder rates for micturition frequency were analyzed in combination with responder rates for one or two PRO outcomes, mirabegron $50 \mathrm{mg}$ demonstrated statistically significantly greater responder rates compared with placebo in all analyses $(P<0.001)$.

\section{Correlation analyses}

For PPBC and the OAB-q symptom bother scale, a negative change from the baseline value indicates patient improvement; thus, a positive Spearman rank correlation coefficient as shown in Table 4 indicates correlation between the improvement from baseline to final visit for PPBC and that for OAB-q symptom bother scale. Meanwhile, for OAB-q total HRQoL, a positive change from baseline value indicates patient improvement; thus, a negative Spearman rank correlation coefficient as shown in Table 4 indicates correlation between the improvement from baseline to final visit for PPBC and that for OAB-q total HRQoL. Both correlations were statistically significant $(P<0.0001)$. There were also significant correlations between change from baseline to final visit in both objective measures - mean number of incontinence episodes per $24 \mathrm{~h}$ and mean number of micturitions per $24 \mathrm{~h}$-and change from baseline to final visit in each of the subjective measures-OAB-q symptom bother scale, OAB-q total HRQoL, and PPBC ( $P<0.0001$, Table 4).

\section{Discussion}

These data extend what has been previously published: in a pooled analysis of three 12-week Phase III studies, mirabegron $50 \mathrm{mg}$ not only resulted in statistically significant improvements versus placebo in change from baseline to final visit in the objective outcomes of mean number of incontinence episodes and mean number of micturitions per $24 \mathrm{~h}$, but also resulted in statistically significant improvements versus placebo in change from baseline to final visit in PPBC, the OAB-q symptom bother scale, OAB-q total HRQoL, and OAB-q subscales of coping, concern, and sleeping, but not social interaction. The social interaction subscale has traditionally been the least responsive of the OAB-q subscales to improvement in patients' wellbeing, so these results are not surprising $[35,36]$.

The improvements produced by mirabegron $50 \mathrm{mg}$ on PROs were also manifest in the proportion of subjects in 
Fig. 2 Adjusted mean change (SE) from baseline to final visit in OAB-q total HRQoL and its subscales of coping, concern, sleeping, and social interaction with mirabegron $50 \mathrm{mg}$ and placebo (FAS; pooled data)

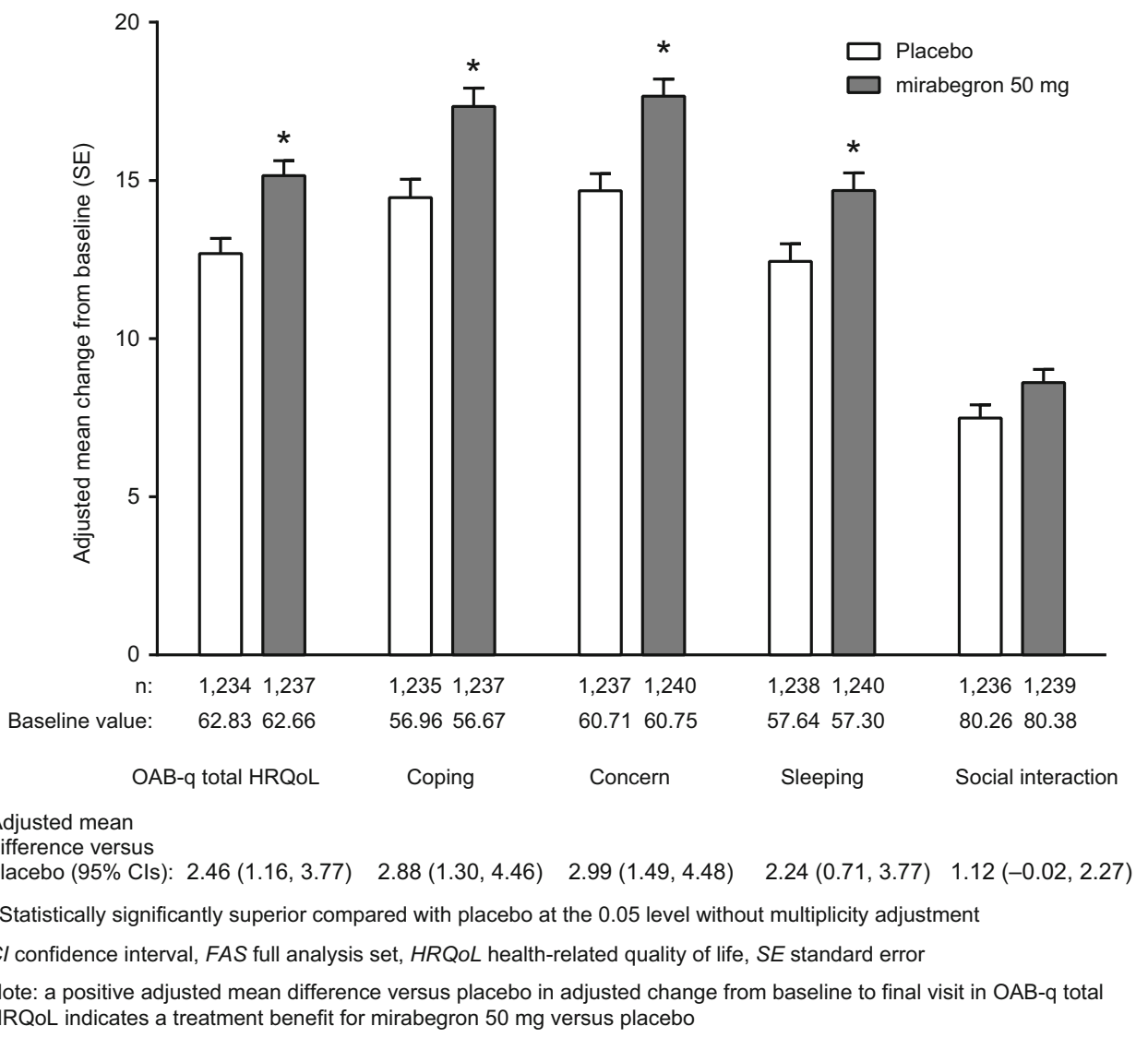

whom the change from baseline exceeded the MID defined for both the OAB-q (10 points) and PPBC (1 point) instruments. Indeed, two-thirds of subjects who received mirabegron $50 \mathrm{mg}$ experienced a change in the OAB-q symptom bother scale that exceeded the MID for that scale (10 points). The MID values for OAB-q have been related to changes in degrees of disease symptomatology that are directly relevant to the patient's experience of the disease, such as resolution of incontinence. Hence, the results demonstrate the meaningfulness of the observed therapeutic benefit experienced by the patient.

There was a significant correlation between change from baseline in PPBC and that in the OAB-q symptom bother scale and OAB-q total HRQoL. Moreover, these correlations were large $(0.60$ and -0.62$)$ [42] and similar to those between PPBC, OAB-q symptom bother scale, and OAB-q HRQoL reported by Coyne and co-workers [43] in a similar post hoc analysis of data from a 12-week open-label trial of tolterodine extended release. These results indicate directional consistency in the response of these PROs to mirabegron $50 \mathrm{mg}$.

Incontinence is a major symptom of $\mathrm{OAB}$, occurring in about one-third of patients, and is associated with significant morbidity, reduction in QoL, and serious limitations to activities of daily living [44]. QoL scores in OAB patients with incontinence have been shown to be consistently lower than in $\mathrm{OAB}$ patients without incontinence [44]. A statistically significant difference between mirabegron $50 \mathrm{mg}$ and placebo in the percentage of patients who achieved a $50 \%$ or greater reduction in incontinence frequency at final visit has been seen previously [32]. In the post hoc analyses described here, the unique approach was taken to identify the proportion of patients who simultaneously achieved a $50 \%$ or greater reduction in incontinence frequency at final visit and the MID in one or two PROs. In all the analyses conducted, mirabegron $50 \mathrm{mg}$ resulted in statistically significantly higher composite responder rates than placebo. Moreover, improvements in both incontinence and micturition frequency were statistically significantly correlated with improvements in each of PPBC, the OAB-q symptom bother scale, and OAB-q total HRQoL. These correlation coefficients were mostly of moderate magnitude (0.30-0.49) [42] and, regardless of which PRO was examined, were similar for incontinence and micturition frequency. A number of studies have demonstrated the favorable effects of several antimuscarinics on a number of different QoL measures [45-49] and a small to moderate, but statistically significant correlation between improvement in number of urgency urinary incontinence episodes and PPBC has been 
Table 3 Single, double, and triple responder analyses for the pooled mirabegron $50 \mathrm{mg}$ group versus placebo

\begin{tabular}{|c|c|c|c|}
\hline Responders ${ }^{\mathrm{a}}$ for: & $\begin{array}{l}\text { Difference versus } \\
\text { placebo } \%(95 \% \mathrm{CIs})^{\mathrm{b}}\end{array}$ & Odds ratio $(95 \% \mathrm{CIs})^{\mathrm{c}}$ & $P$ value $^{\mathrm{c}}$ \\
\hline \multicolumn{4}{|l|}{ Single responder criterion } \\
\hline Incontinence (FAS-I) & $9.9(5.5,14.4)$ & $1.54(1.26,1.89)$ & $<0.001$ \\
\hline Micturitions (FAS) & $7.0(3.6,10.4)$ & $1.57(1.30,1.89)$ & $<0.001$ \\
\hline PPBC (FAS) & $2.8(-1.2,6.7)$ & $1.18(0.99,1.39)$ & 0.059 \\
\hline OAB-q symptom bother score (FAS) & $8.3(4.5,12.1)$ & $1.43(1.21,1.70)$ & $<0.001$ \\
\hline OAB-q total HRQoL (FAS) & $7.9(4.0,11.8)$ & $1.46(1.23,1.74)$ & $<0.001$ \\
\hline \multicolumn{4}{|l|}{ Double responder criteria } \\
\hline Incontinence and PPBC (FAS-I) & $6.8(1.9,11.6)$ & $1.37(1.11,1.68)$ & 0.003 \\
\hline Incontinence and OAB-q symptom bother score (FAS-I) & $15.2(10.4,20.0)$ & $1.87(1.53,2.29)$ & $<0.001$ \\
\hline Incontinence and OAB-q total HRQoL (FAS-I) & $10.9(6.1,15.7)$ & $1.60(1.30,1.97)$ & $<0.001$ \\
\hline Micturitions and PPBC (FAS) & $3.9(0.8,7.1)$ & $1.42(1.14,1.77)$ & 0.001 \\
\hline Micturitions and OAB-q symptom bother score (FAS) & $6.7(3.4,10.0)$ & $1.59(1.30,1.95)$ & $<0.001$ \\
\hline Micturitions and OAB-q total HRQoL (FAS) & $6.0(3.0,9.1)$ & $1.63(1.31,2.02)$ & $<0.001$ \\
\hline \multicolumn{4}{|l|}{ Triple responder criteria } \\
\hline $\begin{array}{l}\text { Incontinence and PPBC and OAB-q symptom bother score } \\
\text { (FAS-I) }\end{array}$ & $9.1(4.2,13.9)$ & $1.55(1.24,1.93)$ & $<0.001$ \\
\hline Incontinence and PPBC and OAB-q total HRQoL (FAS-I) & $8.4(3.6,13.2)$ & $1.51(1.20,1.90)$ & $<0.001$ \\
\hline Micturitions and PPBC and OAB-q symptom bother score (FAS) & $3.5(0.4,6.6)$ & $1.42(1.12,1.79)$ & 0.003 \\
\hline Micturitions and PPBC and OAB-q total HRQoL (FAS) & $3.6(0.7,6.5)$ & $1.47(1.15,1.88)$ & 0.002 \\
\hline
\end{tabular}

$C I$ confidence interval, $F A S$ full analysis set, $F A S-I$ FAS-incontinence, $H R Q o L$ health-related quality of life, $P P B C$ patient perception of bladder condition

${ }^{a}$ Responder definitions: incontinence, $\geq 50 \%$ reduction in incontinence episodes per $24 \mathrm{~h}$ from baseline to final visit; micturitions, $\leq 8$ micturitions per $24 \mathrm{~h}$ at final visit; PPBC, OAB-q symptom bother score, and OAB-q total HRQoL, change from baseline to final visit $\geq$ minimally important difference (10 points for OAB-q total HRQoL and OAB-q symptom bother score and 1 point for PPBC

b $95 \%$ two-sided CIs for the differences between mirabegron $50 \mathrm{mg}$ and placebo in proportions of responders are based on normal approximation

${ }^{c}$ Odds ratios, corresponding two-sided $95 \% \mathrm{CIs}$, and $P$ values are derived from a logistic regression model including treatment group, sex, study, and baseline value(s)

Table 4 Spearman rank order correlation coefficients between objective and subjective outcome measures; pooled mirabegron 50 mg and placebo data

Spearman rank
correlation

coefficient

Correlation between change from baseline to final visit in

PPBC (FAS) and

OAB-q symptom bother score

$0.62<0.0001$

OAB-q total HRQoL

$-0.60$

$<0.0001$

Mean number of incontinence episodes per $24 \mathrm{~h}$ (FAS-I) and

OAB-q symptom bother score

$0.40<0.0001$

OAB-q total HRQoL

$-0.33$

$<0.0001$

PPBC

$0.22<0.0001$

Mean number of micturitions per $24 \mathrm{~h}$ (FAS) and

$\begin{array}{lrr}\text { OAB-q symptom bother score } & 0.42 & <0.0001 \\ \text { OAB-q total HRQoL } & -0.37 & <0.0001 \\ \text { PPBC } & 0.31 & <0.0001\end{array}$

$F A S$ full analysis set, FAS-I FAS-incontinence, $H R Q o L$ health-related quality of life, $O A B$ - $q$ overactive bladder questionnaire, $P P B C$ patient perception of bladder condition 
reported in a 12-week trial of tolterodine extended release [50]. However, no studies of antimuscarinics have evaluated composite responder rates as done here.

In conclusion, it appears that the improvements in objective outcome measures seen with mirabegron $50 \mathrm{mg}$ are mirrored by statistically significant improvements in the clinically relevant PRO measurements of OAB-q total HRQoL, PPBC, and $\mathrm{OAB}-\mathrm{q}$ symptom bother scale. Moreover, there is directional consistency in the effect of mirabegron $50 \mathrm{mg}$ across the disparate domains measured by various objective outcomes and PROs. Thus, improvement in objective outcomes translates into a meaningful clinical benefit; the OAB-q and PPBC appear to provide a clinically relevant perspective on $\mathrm{OAB}$ management, and the objective outcomes of incontinence and micturition frequency appear to be adequate proxies of patient experience. The results bolster the view that mirabegron may be a good treatment option for $\mathrm{OAB}$ patients as improvements in HRQoL measures are likely to be reflected in high patient satisfaction. Nonetheless, studies that specifically evaluate patient satisfaction are necessary to confirm this suggestion. In addition, studies examining patient adherence with mirabegron are required; patient adherence with antimuscarinics, the current mainstay of treatment for $\mathrm{OAB}$, is poor, largely due to intolerable side effects, and it will be interesting to see whether mirabegon's favorable effects on QoL measures translate into good adherence levels.

Acknowledgments The study and editorial assistance were funded by Astellas Pharma. The authors would like to thank Aideen Young, Ph.D., of Envision Scientific Solutions for editorial assistance.

Open Access This article is distributed under the terms of the Creative Commons Attribution License which permits any use, distribution, and reproduction in any medium, provided the original author(s) and the source are credited.

\section{References}

1. Haylen, B. T., de Ridder, D., Freeman, R. M., et al. (2010). An International Urogynecology Association (IUGA)/International Continence Society (ICS) joint report on the terminology for female pelvic floor dysfunction. Neurourology and Urodynamics, 29, 4-20.

2. Irwin, D. E., Milsom, I., Hunskaar, S., et al. (2006). Populationbased survey of urinary incontinence, overactive bladder, and other lower urinary tract symptoms in five countries: Results of the EPIC study. European Urology, 50, 1306-1315.

3. Milsom, I., Abrams, P., Cardozo, L., Roberts, R. G., Thüroff, J., \& Wein, A. J. (2001). How widespread are the symptoms of an overactive bladder and how are they managed? A populationbased prevalence study. BJU International, 87(9), 760-766.

4. Milsom, I., \& Irwin, D. E. (2007). A cross-sectional, populationbased, multinational study of the prevalence of overactive bladder and lower urinary tract symptoms: Results from the EPIC study. European Urology Supplements, 6, 4-9.
5. Stewart, W. F., Van Rooyen, J. B., Cundiff, G. W., et al. (2003). Prevalence and burden of overactive bladder in the United States. World Journal of Urology, 20, 327-336.

6. Coyne, K. S., Sexton, C. C., Irwin, D. E., Kopp, Z. S., Kelleher, C. J., \& Milsom, I. (2008). The impact of overactive bladder, incontinence and other lower urinary tract symptoms on quality of life, work productivity, sexuality and emotional well-being in men and women: results from the EPIC study. BJU International, 101(11), 1388-1395.

7. Coyne, K. S., Kvasz, M., Ireland, A. M., Milsom, I., Kopp, Z. S., \& Chapple, C. R. (2012). Urinary incontinence and its relationship to mental health and health-related quality of life in men and women in Sweden, the United Kingdom, and the United States. European Urology, 61(1), 88-95.

8. Sexton, C. C., Coyne, K. S., Thompson, C., Bavendam, T., Chen, C. I., \& Markland, A. (2011). Prevalence and effect on health-related quality of life of overactive bladder in older Americans: Results from the epidemiology of lower urinary tract symptoms study. Journal of the American Geriatric Society, 59(8), 1465-1470.

9. Coyne, K. S., Sexton, C. C., Kopp, Z. S., Ebel-Bitoun, C., Milsom, I., \& Chapple, C. R. (2011). The impact of overactive bladder on mental health, work productivity and health-related quality of life in the UK and Sweden: Results from EpiLUTS. BJU International, 108(9), 1459-1471.

10. Coyne, K. S., Payne, C., Bhattacharyya, S. K., Revicki, D. A., Thompson, C., Corey, R., et al. (2004). The impact of urinary urgency and frequency on health-related quality of life in overactive bladder: Results from a national community survey. Value Health, 7(4), 455-463.

11. Coyne, K. S., Wein, A. J., Tubaro, A., Sexton, C. C., Thompson, C. L., Kopp, Z. S., et al. (2009). The burden of lower urinary tract symptoms: Evaluating the effect of LUTS on health-related quality of life, anxiety and depression: EpiLUTS. BJU International, 103(Suppl 3), 4-11.

12. Milsom, I., Kaplan, S. A., Coyne, K. S., Sexton, C. C., \& Kopp, Z. S. (2012). Effect of bothersome overactive bladder symptoms on health-related quality of life, anxiety, depression, and treatment seeking in the United States: Results from EpiLUTS. Urology, 80(1), 90-96.

13. Liberman, J. N., Hunt, T. L., Stewart, W. F., Wein, A., Zhou, Z., Requla Herzog, A., et al. (2001). Health-related quality of life among adults with symptoms of overactive bladder: Results from a U.S. community-based survey. Urology, 57, 1044-1050.

14. Coyne, K. S., Wein, A., Nicholson, S., Kvasz, M., Chen, C. I., \& Milsom, I. (2013). Comorbidities and personal burden of urgency urinary incontinence: A systematic review. International Journal of Clinical Practice, 67(10), 1015-1033.

15. Abrams, P., Artibani, W., Gajewski, J. B., \& Hussain, I. (2006). Assessment of treatment outcomes in patients with overactive bladder: Importance of objective and subjective measures. Urology, 68(2 Suppl), 17-28.

16. Shah, S., \& Nitti, V.W. (2009). Defining efficacy in the treatment of overactive bladder syndrome. Review in Urology, 11(4), 196-202.

17. Brubaker, L., Chapple, C., Coyne, K. S., \& Kopp, Z. (2006). Patientreported outcomes in overactive bladder: Importance for determining clinical effectiveness of treatment. Urology, 68(2 Suppl), 3-8.

18. Fairclough, D. L. (2004). Patient reported outcomes as endpoints in medical research. Statistical Methods in Medical Research, 13, $115-138$.

19. Speight, J., \& Barendse, S. M. (2010). FDA guidance on patient reported outcomes. BMJ, 340, c2921.

20. Black, N., \& Jenkinson, C. (2009). How can patients' views of their care enhance quality improvement? British Medical Journal, 339, b2495. 
21. Khullar, V. (2012). Patient-reported outcomes and different approaches to urinary parameters in overactive bladder: What should we measure? International Urogynecology, 23, 179-192.

22. Mattiasson, A., Djurhuus, J. C., Fonda, D., Lose, G., Nordling, J., \& Stöhrer, M. (1998). Standardization of outcome studies in patients with lower urinary tract dysfunction: A report on general principles from the Standardisation Committee of the International Continence Society. Neurourology and Urodynamics, 17(3), 249-253.

23. Dmochowski, R. R., Sand, P. K., Zinner, N. R., Gittelman, M. C., Davila, G. W., \& Sanders, S. W. (2003). Transdermal Oxybutynin Study Group. Comparative efficacy and safety of transdermal oxybutynin and oral tolterodine versus placebo in previously treated patients with urge and mixed urinary incontinence. Urology, 62(2), 237-242.

24. Yu, Y. F., Nichol, M. B., Yu, A. P., \& Ahn, J. (2005). Persistence and adherence of medications for chronic overactive bladder/ urinary incontinence in the California Medicaid program. Value in Health, 8(4), 495-505.

25. Shaya, F. T., Blume, S., Gu, A., Zyczynski, T., \& Jumadilova, Z. (2005). Persistence with overactive bladder pharmacotherapy in a Medicaid population. American Journal of Managed Care, 11(4 Suppl), S121-S129.

26. Varadharajan, S., Jumadilova, Z., Girase, P., \& Ollendorf, D. A. (2005). Economic impact of extended-release tolterodine versus immediate- and extended-release oxybutynin among commercially insured persons with overactive bladder. American Journal of Managed Care, 11(4 Suppl), S140-S149.

27. D’Souza, A. O., Smith, M. J., Miller, L. A., Doyle, J., \& Ariely, R. (2008). Persistence, adherence, and switch rates among extended-release and immediate-release overactive bladder medications in a regional managed care plan. Journal of Managed Care Pharmacy, 14(3), 291-301.

28. Zinner, N., Kobashi, K. C., Ebinger, U., Viegas, A., Egermark, M., Quebe-Fehling, E., et al. (2008). Darifenacin treatment for overactive bladder in patients who expressed dissatisfaction with prior extended-release antimuscarinic therapy. International Journal of Clinical Practice, 62(11), 1664-1674.

29. Khullar, V., Amarenco, G., Angulo, J. C., et al. (2013). Efficacy and tolerability of mirabegron, a $\beta 3$-adrenoceptor agonist, in patients with overactive bladder: Results from a randomised EuropeanAustralian phase 3 trial. European Urology, 63, 283-295.

30. Nitti, V., Auerbach, S., Martin, N., et al. (2013). Results of a randomized phase III trial of mirabegron in patients with overactive bladder. Journal of Urology, 189, 1388-1395.

31. Herschorn, S., Barkin, J., Castro-Diaz, D., Frankel, J. M., EspunaPons, M., Gousse, A. E., et al. (2013). A phase III, randomized, double-blind, parallel-group, placebo-controlled, multicenter study to assess the efficacy and safety of the beta- 3 agonist mirabegron in patients with symptoms of overactive bladder. Urology, 82(2), 313-320.

32. Nitti, V., Herschorn, S., Khullar, V., Cambronero, J., Angulo, J., Blauwet, M. B., et al. (2013). Efficacy of mirabegron in patients with overactive bladder: A pre-specified pooled analysis of three randomised, double-blind, placebo-controlled, phase III studies. International Journal of Clinical Practice, 67(7), 619-632.

33. Pavesi, M., Devlin, N., Hakimi, Z., Nazir, J., Herdman, M., Hoyle, C., et al. (2013). Understanding the effects on HR-QoL of treatment for overactive bladder: A detailed analysis of EQ-5D clinical trial data for mirabegron. Journal of Medical Economics, 16, 866-876.

34. Coyne, K., Revicki, D., Hunt, T., Corey, R., Stewart, W., Bentkover, J., et al. (2002). Psychometric validation of an overactive bladder symptom and health-related quality of life questionnaire: The OABq. Quality of Life Research, 11(6), 563-574.

35. Coyne, K. S., Matza, L. S., \& Thompson, C. L. (2005). The responsiveness of the overactive bladder questionnaire (OAB-q). Quality of Life Research, 14(3), 849-855.
36. Coyne, K. S., Matza, L. S., Thompson, C., Jumadilova, Z., \& Bavendam, T. (2007). The responsiveness of the OAB-q among OAB patient subgroups. Neurourology and Urodynamics, 26(2), 196-203.

37. Matza, L. S., Thompson, C. L., Krasnow, J., Brewster-Jordan, J., Zyczynski, T., \& Coyne, K. S. (2005). Test-retest reliability of four questionnaires for patients with overactive bladder: The overactive bladder questionnaire (OAB-q), patient perception of bladder condition (PPBC), urgency questionnaire (UQ), and the primary $\mathrm{OAB}$ symptom questionnaire (POSQ). Neurourology and Urodynamics, 24(3), 215-225.

38. Coyne, K. S., Matza, L. S., Kopp, Z., \& Abrams, P. (2006). The validation of the patient perception of bladder condition (PPBC): A single-item global measure for patients with overactive bladder. European Urology, 49, 1079-1086.

39. Jaeschke, R., Singer, J., \& Guyatt, G. H. (1989). Measurement of health status. Ascertaining the minimal clinically important difference. Controlled Clinical Trials, 10(4), 407-415.

40. Dyer, K. Y., Xu, Y., Brubaker, L., Nygaard, I., Markland, A., Rahn, D., et al. (2011). Urinary incontinence treatment network (UITN). Minimum important difference for validated instruments in women with urge incontinence. Neurourology and Urodynamics, 30(7), 1319-1324.

41. Coyne, K. S., Matza, L. S., Thompson, C. L., Kopp, Z. S., \& Khullar, V. (2006). Determining the importance of change in the overactive bladder questionnaire. Journal of Urology, 176(2), 627-632.

42. Cohen, J. (1988). Statistical power analysis for the behavioral sciences (2nd ed.). Hillsdale, NJ: Lawrence Erlbaum Associates.

43. Coyne, K. S., Elinoff, V., Gordon, D. A., Deng, D. Y., Brodsky, M., Glasser, D. B., et al. (2008). Relationships between improvements in symptoms and patient assessments of bladder condition, symptom bother and health-related quality of life in patients with overactive bladder treated with tolterodine. International Journal of Clinical Practice, 62(6), 925-931.

44. Stewart, K., McGhan, W. F., Offerdahl, T., \& Corey, R. (2002). Overactive bladder patients and role of the pharmacist. Journal of the American Pharmacists Association, 42(3), 469-476.

45. Kelleher, C. J., Reese, P. R., Pleil, A. M., \& Okano, G. J. (2002). Health-related quality of life of patients receiving extendedrelease tolterodine for overactive bladder. American Journal of Managed Care, 8(19 Suppl), S608-S615.

46. Kelleher, C. J., Dmochowski, R. R., Berriman, S., Kopp, Z. S., \& Carlsson, M. (2012). Sustained improvement in patient-reported outcomes during long-term fesoterodine treatment for overactive bladder symptoms: Pooled analysis of two open-label extension studies. BJU International, 110(3), 392-400.

47. Homma, Y., \& Kawabe, K. (2004). Health-related quality of life of Japanese patients with overactive bladder treated with extended-release tolterodine or immediate-release oxybutynin: A randomized, placebo-controlled trial. World Journal of Urology, 22(4), 251-256.

48. Siami, P., Seidman, L. S., \& Lama, D. (2002). A multicenter, prospective, open-label study of tolterodine extended-release $4 \mathrm{mg}$ for overactive bladder: The speed of onset of therapeutic assessment trial (STAT). Clinical Therapeutics, 24(4), 616-628.

49. Roberts, R., Bavendam, T., Glasser, D. B., Carlsson, M., Eyland, N., \& Elinoff, V. (2006). Tolterodine extended release improves patient-reported outcomes in overactive bladder: Results from the IMPACT trial. International Journal of Clinical Practice, 60(6), $752-758$.

50. Van Kerrebroeck, P. E., Kelleher, C. J., Coyne, K. S., Kopp, Z., Brodsky, M., \& Wang, J. T. (2009). Correlations among improvements in urgency urinary incontinence, health-related quality of life, and perception of bladder-related problems in incontinent subjects with overactive bladder treated with tolterodine or placebo. Health and Quality of Life Outcomes, 7, 131. 